\title{
Ground-based millimeter-wave observation of stratospheric ClO over Atacama, Chile in the mid-latitude Southern Hemisphere
}

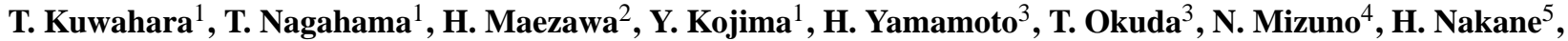 \\ Y. Fukui ${ }^{3}$, and A. Mizuno ${ }^{1}$ \\ ${ }^{1}$ Solar-Terrestrial Environment Laboratory, Nagoya University, Nagoya, Aichi, Japan \\ ${ }^{2}$ Department of Physics, Osaka Prefecture University, Sakai, Osaka, Japan \\ ${ }^{3}$ Department of Astrophysics, Nagoya University, Nagoya, Aichi, Japan \\ ${ }^{4}$ National Astronomical Observatory of Japan, Mitaka, Tokyo, Japan \\ ${ }^{5}$ National Institute for Environmental Studies, Tsukuba, Ibaraki, Japan \\ Correspondence to: T. Kuwahara (kuwahara@stelab.nagoya-u.ac.jp)
}

Received: 24 January 2012 - Published in Atmos. Meas. Tech. Discuss.: 27 February 2012

Revised: 25 July 2012 - Accepted: 9 August 2012 - Published: 1 November 2012

\begin{abstract}
We have performed ground-based measurements of stratospheric chlorine monoxide $(\mathrm{ClO})$ during the summer in 2009 over the Atacama highland, Chile, a new observing site in the mid-latitude region in the Southern Hemisphere, by using a millimeter-wave spectroscopic radiometer. The radiometer, equipped with a superconducting receiver and a digital Fourier spectrometer, was developed by Nagoya University, and the new observing system provides us high sensitivity and stable performance to measure the very weak $\mathrm{ClO}$ lines. The receiver noise temperature of the superconducting receiver is $170 \mathrm{~K}$ in $\mathrm{DSB}$. To reveal the diurnal variation of $\mathrm{ClO}$, we retrieved the vertical mixing ratio profiles by the weighted-damped least-squares algorithm applied for the spectral data at $203 \mathrm{GHz}$ obtained between 5 and 16 December 2009. The total error on the retrieval is estimated to be $20 \%$ to $30 \%$ in an altitude range from $40 \mathrm{~km}$ to $50 \mathrm{~km}$. The amplitude of the diurnal variation is estimated as $33 \%$ of the daytime average at $40 \mathrm{~km}$. The observed time variation shows a pattern similar to that of the previous works observed in the northern mid-latitude region.
\end{abstract}

\section{Introduction}

Enforcement of the Montreal Protocol is expected to lead to the decline of ozone-depleting substances (ODSs) including CFCs and thus to an increase in the abundance of stratospheric ozone. Understanding $\mathrm{ClO}$ chemistry is key to understanding chlorine chemistry and ozone recovery processes (Molina and Rowland, 1974). ClO accounts for $~$ $25 \%$ of the inorganic chlorine in the middle atmosphere; the remaining $\sim 75 \%$ consists mainly of $\mathrm{HCl}$ (Zander et al., 1996). Ground- and satellite-based infrared measurements indicate that $\mathrm{HCl}$ levels in the stratosphere have been decreasing since 1997 (e.g., Rinsland et al., 2003; Mahieu et al., 2005; WMO, 2011), and stratospheric $\mathrm{ClO}$ has been declining at a rate of $-0.9 \% \mathrm{yr}^{-1}$ since 1995 . Despite these declines, no significant recovery of stratospheric ozone levels has been observed (WMO, 2011).

To determine the causes of the delay in ozone recovery, additional accurate observations of trends not only in ozone levels but also the levels of chlorine-containing species, including $\mathrm{ClO}$, are needed. In particular, information about longand short-term variations in stratospheric $\mathrm{ClO}$, such as diurnal and seasonal variations, is necessary. Ricaud et al. (2000) and Nedoluha et al. (2011) used satellite- and ground-based millimeter-wave measurements to investigate seasonal variations in $\mathrm{ClO}$ levels. Information about the amplitude and the shape of the diurnal variation profile is necessary for derivation of trends and seasonal variations for molecules like $\mathrm{ClO}$, the levels of which vary substantially between day and night. Actually, some satellite measurements are carried out for a limited portion of the day, for example at dusk and dawn. In such a case, better understanding of the diurnal variation is essentially important to extrapolate the daytime or nighttime value (e.g., Jones et al., 2011). In addition, detailed study of 
the diurnal variation leads to better understanding of photochemical processes, because the diurnal variation tends to reflect the short-term photochemical processes rather than the contamination due to the other longer-term ( $>1$ day) processes such as atmospheric transport (Ko and Sze, 1984).

However, measuring diurnal variations in $\mathrm{ClO}$ levels is difficult because of its weak spectral intensity. The first observation of the diurnal variation of mid-latitude $\mathrm{ClO}$ over a full $24 \mathrm{~h}$ was done at $287 \mathrm{GHz}$ over Mauna Kea, Hawaii (Solomon et al., 1984). Ricaud et al. (1997) investigated altitudinal differences in the diurnal variation of $\mathrm{ClO}$ between 25 and $50 \mathrm{~km}$ by observing the $278 \mathrm{GHz}$ spectral lines over the Plateau de Bure, France. Ricaud et al. (2000) improved the accuracy of their previous measurements by using the data obtained by the Upper Atmosphere Research Satellite (UARS) with Microwave Limb Sounder (MLS) from 1991 to 1997 within a latitude band from $40^{\circ} \mathrm{N}$ to $50^{\circ} \mathrm{N}$. de Zafra et al. (1994), Raffalski et al. (1998), and Emmons et al. (1995) investigated the diurnal variation of $\mathrm{ClO}$ over the polar regions by means of ground-based observations from Thule in Greenland, Ny-Ålesund in Spitsbergen, and McMurdo Station in Antarctica, respectively, but only Raffalski et al. (1998) presented the variation curve over $24 \mathrm{~h}$.

Because of the difficulty in obtaining spectra of stratospheric $\mathrm{ClO}$, our current knowledge about the behavior of $\mathrm{ClO}$ remains insufficient $26 \mathrm{yr}$ after the first clear evidence of the large diurnal variation was obtained by Solomon et al. (1984). In summary, additional observational data on the diurnal variation of $\mathrm{ClO}$ are necessary, and there have been no ground-based observations from the mid-latitude regions of the Southern Hemisphere.

This work is aimed at collecting the necessary additional data and reports the results of the first ground-based observation of the $\mathrm{ClO}$ diurnal variation from the southern midlatitude region. We first describe the observing system and methods of observation and data reduction. Then we present the retrieval results of the vertical profile of $\mathrm{ClO}$ and discuss the error analysis. And finally, we discuss the $\mathrm{ClO}$ diurnal variation over Atacama highland $\left(23^{\circ} \mathrm{S}, 68^{\circ} \mathrm{W}\right.$, alt. $\left.4800 \mathrm{~m}\right)$ in Chile.

\section{Instrumentation and observations}

\subsection{Instruments}

The $\mathrm{ClO}$ molecule exhibits rotational transition lines in the millimeter wavelength region, and the rotational lines are split by $\Lambda$-doubling and hyperfine structure stemming from magnetic and nuclear quadrupole terms (e.g., Amano et al., 1968). In this study, $J=11 / 2-9 / 2$ lines around $204.346 \mathrm{GHz}$ were observed with an upgraded millimeterwave heterodyne spectroscopic radiometer originally developed by Nagoya University and ULVAC Inc. (Mizuno et al., 2002).
Figure 1 shows the block diagram of the radiometer. The radiometer consists of the quasi-optical system, the heterodyne receiver system, and the spectrometer. For the quasioptical system, we employed offset-Gregorian telescope optics consisting of a paraboloidal mirror and a ellipsoidal mirror. The $10.5 \mathrm{~cm}$ diameter paraboloidal mirror forms a beam with a size of $1.0^{\circ}$ in the full width at half maximum (FWHM) at $204 \mathrm{GHz}$, and the beam direction (i.e., the observing elevation angle) is changed by the flat rotating mirror placed in front of the paraboloidal mirror. A path length modulator (PLM) is installed around the beam-waist between the paraboloidal mirror and ellipsoidal mirror. The PLM consists of a pair of roof-top mirrors, and it smooths and reduces the standing waves that cause an artificial spectral baseline ripple by periodically changing the path length of the optics (Gustincic, 1977; Mizuno et al., 2002).

The receiver frontend is a superconductor-insulatorsuperconductor (SIS) mixer (see, e.g., Tucker and Feldman, 1985, for more details) operated in double sideband (DSB) mode. The SIS mixer and the following high electron mobility transistor (HEMT) amplifier are cryogenically cooled down to $\sim 4$ Kelvin by a closed cycle helium mechanical refrigerator. The equivalent receiver noise temperature of the SIS mixer was $170 \mathrm{~K}$ in DSB at $204.546 \mathrm{GHz}$. The frequency of the local oscillator (LO) was chosen to be $202.446 \mathrm{GHz}$. There are no significant spectral lines except for $\mathrm{ClO}$ in both signal- and image-bands confirmed by using the forward model calculation with molecular line parameters listed in JPL Submillimeter, Millimeter, and Microwave Spectral Line Catalog (Pickett et al., 1998). Concerning the response to the continuum emission that we use for intensity calibration, we assume equal response for both sidebands. This equality has been confirmed by observing ozone spectrum at $203.453 \mathrm{GHz}$ that is close enough to the $\mathrm{ClO}$ line frequency at $204.546 \mathrm{GHz}$. The output from the SIS mixer at $2.1 \mathrm{GHz}$ is processed by the room temperature IF circuits to adjust the frequency and amplitude level appropriate for the backend spectrometer.

The backend spectrometer had been the acousto-optical spectrometer (AOS) in the original radiometer system (Mizuno et al., 2002), but we replaced the spectrometer with a new digital FFT spectrometer in 2009. Since the atmospheric pressure at Atacama highland is about a half of that at the sea level, the cooling efficiency for the electronic devices is reduced by a factor of two. Thus, we put additional cooling mechanism to the original commercial FFT spectrometer to secure stability at Atacama. The FFT spectrometer provides a bandwidth of $1 \mathrm{GHz}$ and a frequency resolution of $70 \mathrm{kHz}$ by using Hanning window apodization. The stability of spectrometer and the whole system is commonly characterized by Allan minimum time (see, e.g., Schieder and Karmer, 2001, for more details), and this value is defined by the minimum point of Allan variance plot. The Allan minimum time of the FFT spectrometer was estimated to be $\sim 1000 \mathrm{~s}$, improved by about two orders of magnitude compared with the previous 


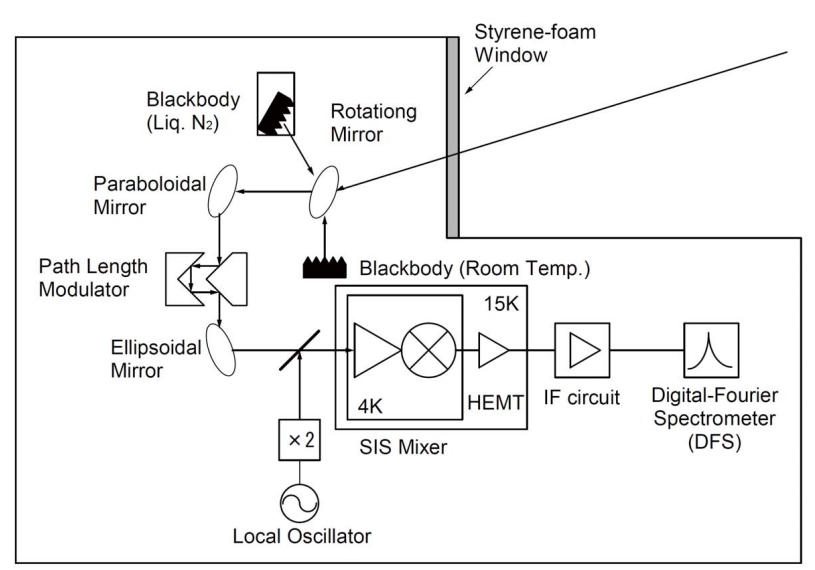

Fig. 1. Block diagram of the millimeter-wave spectroscopic radiometer in Atacama, Chile.

AOS ( $\sim 10$ s). The Allan minimum time of the whole system was estimated to be $\sim 60 \mathrm{~s}$, indicating it is mainly limited by the receiver rather than the spectrometer.

\subsection{Observation period and site}

We observed the stratospheric $\mathrm{ClO}$ from December 2009 to January 2010 at Nagoya University Atacama Atmospheric Observing Station (NATAOS) in Chile $\left(23^{\circ} \mathrm{S}, 68^{\circ} \mathrm{W}\right)$. The altitude of the station is $4800 \mathrm{~m}$ above sea level, providing a very small atmospheric opacity in the millimeter wavelength due to low water vapor pressure, because the tropospheric water vapor is the major agent of absorption of millimeter-wave radiation including stratospheric molecular spectral emission. Atacama highland is one of the best sites to observe very weak stratospheric molecular lines from the ground. A typical optical depth around $204 \mathrm{GHz}$ at Atacama was less than 0.1 during the observing period, as shown later.

\subsection{Observation method}

The ClO spectral lines were obtained by using the elevation switching method (Mizuno et al., 2002). In this method, two different sky directions, one at high elevation and the other at low elevation, are alternately observed. The sky opacity and receiver fluctuations are compensated for by subtracting the high-elevation signal from the low-elevation signal. The high-elevation angle is fixed near the zenith and is referred to as the reference angle. The low-elevation angle varies with sky conditions and is referred to as the observing-sky angle.

Because the contributions of the continuum emission from the lower atmosphere differ for the high and low elevations (owing to the difference in the air mass along the line of sight), a lossy dielectric plate is inserted in the referenceangle beam to equalize the continuum signal levels. However, the air mass changes with time as the sky conditions change, and the level equalization is fine-tuned by adjustment of the observing-sky angle.

Atmospheric gases (and, more generally, translucent media like lossy dielectric plates) not only absorb incident radiation but also emit thermal radiation simultaneously. The thermal radiation intensity is expressed as a brightness temperature or an equivalent temperature of a black body that emits the same amount of radiation energy at the observing frequency. At millimeter wavelengths, thermal radiation intensity is approximated to be proportional to the black-body temperature, owing to the Rayleigh-Jeans law of radiation. The transmission coefficient of the translucent medium is given by $e^{-\tau}$, and the thermal radiation intensity (i.e., brightness temperature) is expressed as $T\left(1-e^{-\tau}\right)$ where $\tau$ is the optical depth of the translucent medium. $T$ corresponds to the brightness temperature of black body at physical temperature of $T$, and is considered to be equal to the physical temperature of the translucent medium.

The output power of the receiver system, $P_{\text {out }}$, is proportional to the brightness temperature of the input signal, $T_{\text {in }}$, and the equivalent temperature of additional system noise, $T_{\text {sys }}$, generated in the radiometer system:

$P_{\text {out }}=\alpha T_{\text {out }}=\alpha\left(T_{\text {in }}+T_{\text {sys }}\right)$,

where $\alpha$ is the proportionality coefficient. In case of optically thin, the intensity of the stratospheric molecular emission line is linearly proportional to the stratospheric path length or air mass. Thus, the observed intensity for the reference sky, $T_{\text {ref }}$, is given by

$$
\begin{aligned}
T_{\text {ref }} & =T_{\text {line }} A_{\text {ref }} e^{-\tau A_{\text {ref }}-\tau_{\text {plate }}}+T_{\text {trop }}\left(1-e^{-\tau A_{\text {ref }}}\right) e^{-\tau_{\text {plate }}} \\
& +T_{\text {plate }}\left(1-e^{-\tau_{\text {plate }}}\right)+T_{\text {sys }},
\end{aligned}
$$

where $T_{\text {line }}$ is the intensity of the stratospheric molecular emission line toward the zenith, $T_{\text {trop }}$ is the equivalent temperature of the troposphere, $\tau$ is the optical depth of the troposphere, and $T_{\text {plate }}$ and $\tau_{\text {plate }}$ are the physical temperature and the optical depth of the lossy dielectric plate, respectively. In addition, $A_{\text {ref }}$ is the air mass factor at the referencesky angle determined by

$A_{\text {ref }}=\frac{1}{\sin \mathrm{EL}_{\mathrm{ref}}}$.

Similarly, the intensity for the observing sky, $T_{\mathrm{obs}}$, is given by

$T_{\mathrm{obs}}=T_{\text {line }} A_{\mathrm{obs}} e^{-\tau A_{\mathrm{obs}}}+T_{\text {trop }}\left(1-e^{-\tau A_{\mathrm{obs}}}\right)+T_{\mathrm{sys}}$,

where $A_{\mathrm{obs}}$ is the air mass factors at the observing-sky angle,

$A_{\mathrm{obs}}=\frac{1}{\operatorname{sinEL}_{\mathrm{obs}}}$.

The observing-sky angle, $\mathrm{EL}_{\mathrm{obs}}$, is automatically adjusted so that the continuum levels of $T_{\mathrm{ref}}$ and $T_{\mathrm{obs}}$ are balanced at the 
outside of the molecular-line frequency. The balancing condition is obtained as

$$
\begin{aligned}
& T_{\text {trop }}\left(1-e^{-\tau A_{\text {ref }}}\right) e^{-\tau_{\text {plate }}}+T_{\text {plate }}\left(1-e^{-\tau_{\text {plate }}}\right) \\
& \approx T_{\text {trop }}\left(1-e^{-\tau A_{\text {obs }}}\right)
\end{aligned}
$$

from Eqs. (2) and (4) by setting that $T_{\text {line }}$ is negligibly small.

The proportionality coefficient, $\alpha$, has to be determined to obtain the intensity scale of the brightness temperature. The coefficient is determined by measurements of two reference black bodies at different physical temperatures, $T_{\text {hot }}$ and $T_{\text {cold }}$, and is expressed in terms of the output powers from the hot and cold black bodies, $P_{\text {hot }}$ and $P_{\text {cold }}$, respectively:

$$
\begin{aligned}
& P_{\text {hot }}=\alpha\left(T_{\text {hot }}+T_{\text {sys }}\right), \\
& P_{\text {cold }}=\alpha\left(T_{\text {cold }}+T_{\text {sys }}\right), \\
& \alpha=\frac{P_{\text {hot }}-P_{\text {cold }}}{T_{\text {hot }}-T_{\text {cold }}} .
\end{aligned}
$$

The optical depth of tropospheric absorbing layer, $\tau$, was measured by "sky tipping" method (Ulich et al., 1980) every $10 \mathrm{~min}$. Finally, from Eqs. (2), (4), and (6), the brightness temperature of the stratospheric $\mathrm{ClO}, T_{\text {line }}$, is derived from the observed quantities at observing sky, $P_{\mathrm{obs}}$, and at reference sky, $P_{\text {ref }}$, as

$T_{\text {line }}=\frac{P_{\text {obs }}-P_{\text {ref }}}{\alpha\left(A_{\text {obs }} e^{\left.-\tau A_{\text {obs }}-A_{\text {ref }} e^{-\tau A_{\text {ref }}-\tau_{\text {plate }}}\right)} .\right.}$

In our measurement, the hot reference was a radio absorber at room temperature (i.e., $T_{\text {hot }} \sim 300 \mathrm{~K}$ ), and the cold reference is an absorber soaked in liquid nitrogen (i.e., $T_{\text {cold }} \sim 73 \mathrm{~K}$ ) at an altitude of $4800 \mathrm{~m}$. $\tau_{\text {plate }}$ was estimated from Eq. (6) as

$\tau_{\text {plate }}=\tau\left(A_{\text {obs }}-A_{\text {ref }}\right)$,

on the assumption that $T_{\text {trop }}=T_{\text {plate }}$. Two acrylic plates with thicknesses of 1 and $5 \mathrm{~mm}$ were used in our measurements, and the corresponding $\tau_{\text {plate }}$ values were estimated to be 0.04 and 0.3 , respectively. These plates were changed manually as the sky conditions changed, and the observing-sky angle was set between $15^{\circ}$ and $45^{\circ}$.

\section{Data analysis}

\subsection{Data selection}

For determination of the diurnal variation of stratospheric $\mathrm{ClO}$ levels, the dataset was divided into the 3-h bins, and the spectral data were averaged to improve the signal-to-noise ratio. Although the channel-to-channel random noise was reduced by the averaging, artificial features of the spectral baseline could not always be eliminated completely. Baseline ripples caused by standing waves in the optical system and residuals due to incomplete subtraction of the continuum level in the elevation switching were considered to be the origins of the artificial features. These features were more significant when the sky conditions were bad, because the line intensity became smaller than the features, owing to the large absorption. Therefore, we selected data obtained under good observing conditions.

Figure 2 shows the time dependence of the sky optical depth from 1 December 2009, to 17 January 2010. Even in the Atacama highland, the water vapor pressure increases during part of the summer (during what is referred to as Bolivian winter). In 2009, the Bolivian winter seemed to start around 17 December, after which the sky optical depth abruptly increased. Before 5 December, the sky optical depth was a little bad and the rms noise on the spectra was worse than that obtained after December 5. Therefore, only data obtained from 5-16 December were analyzed. Data obtained at $\tau>0.15$ and a balanced observing-sky angle $\left(\mathrm{EL}_{\mathrm{obs}}\right)$ of $<15^{\circ}$ or $>25^{\circ}$ were excluded. The lower limit of $\mathrm{EL}_{\text {obs }}$ was set to avoid the radiometer beam suppression by a mountain that is located at the direction of observation. The upper limit was set to maintain a sufficient difference between the reference air mass and the observing-sky air mass.

\subsection{Retrieval method}

The vertical profiles of the $\mathrm{ClO}$ volume mixing ratio were retrieved by means of a weighted-damped least-squares fitting algorithm (Nagahama et al., 1999) based on inversion methods such as the optimal estimation method (Rodgers, 1976). In Rodgers's method, the $\mathrm{ClO}$ volume mixing ratio, $R_{\text {ret }}$, is estimated as

$$
\begin{aligned}
R_{\text {ret }}= & R_{\text {a priori }}+\mathbf{S}_{R} \mathbf{W}^{T}\left(\mathbf{W} \mathbf{S}_{R} \mathbf{W}^{T}+\mathbf{S}_{\mathrm{sp}}\right)^{-1} \\
& \left(T_{\text {line }}-\mathbf{W} R_{\text {a priori }}\right),
\end{aligned}
$$

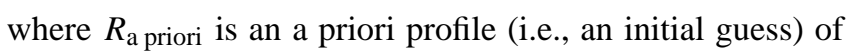
the volume mixing ratio, $T_{\text {line }}$ is the intensity of $\mathrm{ClO}$ spectra, $\mathbf{W}$ is the weighting function for the spectrum, and $\mathbf{S}_{R}$ and $\mathbf{S}_{\mathrm{sp}}$ are the covariances of the a priori profile and the measured spectrum, respectively. Nagahama et al. (1999) showed that $\mathbf{S}_{R}=\zeta^{2} \mathbf{U}$, where $\mathbf{U}$ is the unit matrix and $\zeta$ is a proportionality constant, because $\mathbf{S}_{R}$ is independent of altitude. In addition, $\mathbf{S}_{\mathrm{sp}}=\varepsilon^{2} \mathbf{U}$ where $\varepsilon$ is a proportionality constant, because the root-mean-square (rms) noise of the spectrum is expected to be the same over the observed frequency range and the channel-to-channel correlation on the spectrum is negligible in this study (Nagahama et al., 1999). Substituting these equalities into Eq. (12) gives

$$
\begin{aligned}
R_{\text {ret }}= & R_{\text {a priori }}+\mathbf{W}^{T}\left[\mathbf{W} \mathbf{W}^{T}+(\varepsilon / \zeta)^{2}\right]^{-1} \\
& \left(T_{\text {line }}-\mathbf{W} R_{\text {a priori }}\right),
\end{aligned}
$$

where $(\varepsilon / \zeta)^{2}$ is an adjustable parameter that is empirically determined to improve the vertical resolution and to suppress the artificial oscillation of the retrieval solution. We set 


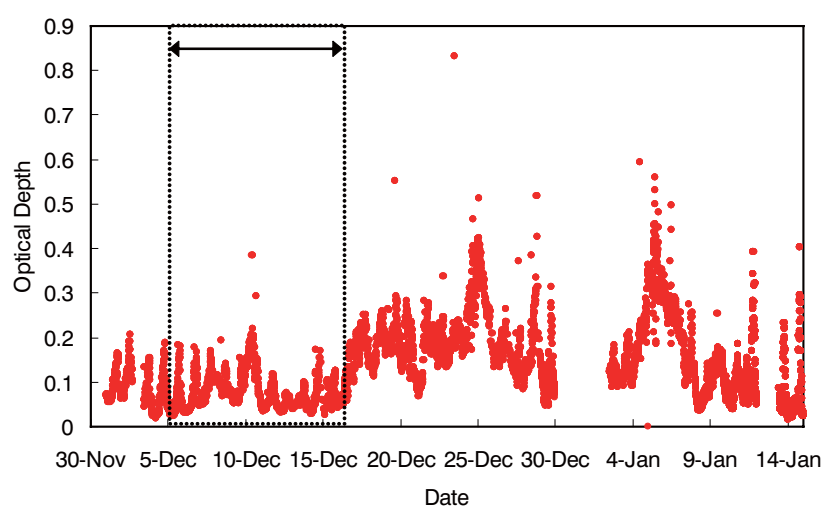

Fig. 2. Time series of optical depth over Atacama from 1 December 2009 to 17 January 2010. The arrow indicates the period chosen for data analysis in this study, from 5 to 16 December 2009.

$(\varepsilon / \zeta)^{2}$ to 0.0016 in this study. The averaging kernel, $\mathbf{A}$, corresponding to the vertical resolution is given by

$\mathbf{A}=\mathbf{W}^{T}\left[\mathbf{W} \mathbf{W}^{T}+(\varepsilon / \zeta)^{2}\right]^{-1} \mathbf{W}$.

When this algorithm is used, the vertical resolution no longer depends on the rms noise of each spectrum (Nagahama et al., 1999), and the diurnal variation at a fixed vertical resolution can be compared for all retrieved profiles. The algorithm was applied to the central part of the averaged $\mathrm{ClO}$ spectra with a frequency range of $150 \mathrm{MHz}$ to avoid the contamination of the baseline ripple and spurious signal that cannot be removed by simple sinusoidal functions. The averaged spectra were smoothed by taking a 5-ch moving average and a 7-ch by binding up and by subtracting an artificial continuum baseline by fitting a fourth-polynomial for the frequency range outside of the $\mathrm{ClO}$ emission line. Vertical profiles of temperature and pressure are necessary for the retrieval calculation. Daily temperature and pressure data were obtained from National Centers for Environmental Prediction (NCEP) reanalysis data (Lait et al., 2009) by means of the NASA Goddard Space Flight Center automailer system. However, because the maximum altitude of the NCEP data is $49 \mathrm{~km}$, the vertical temperature and pressure profiles were extrapolated above $49 \mathrm{~km}$ with the Committee on Space Research International Reference Atmosphere (CIRA86 Rees et al., 1990). For the a priori profile of the $\mathrm{ClO}$ volume mixing ratio, an average of daytime and the nighttime values from the MIPAS model atmosphere (2001) in the mid-latitude region was used. The molecular line parameters were taken from the Jet Propulsion Laboratory Submillimeter, Millimeter,and Microwave Spectral Line Catalog (Pickett et al., 1998).

\section{Results and discussion}

\subsection{Retrieved vertical profile}

Figure 3 shows a typical averaged $\mathrm{ClO}$ spectrum over the Atacama highland, which was obtained between 12:00 and 15:00 local time (LT) and averaged over 12 days. Figure 4 shows the vertical profile of the $\mathrm{ClO}$ volume mixing ratio retrieved from the spectrum, along with the a priori profile used for the retrieval.

The retrieval algorithm was evaluated by comparison of the observed spectrum with the expected spectrum calculated by means of a forward model calculation (Fig. 3, blue line) involving integration of the derivative radiative transfer equation along the line of sight by assuming a symmetrical Voigt line-profile function for the given vertical profiles of molecular mixing ratio, temperature, and pressure. The rms residual between the observed and forward model spectra (Fig. 3, lower panel) was $<1.8 \mathrm{mK}$ for all the retrieval results in this study.

The vertical resolution was defined as the full width at half maximum of the averaging kernel of the retrieval for each altitude (Fig. 5). As mentioned in Sect. 3.2, the adjustable parameter $(\varepsilon / \zeta)^{2}$ was used instead of the covariance of the vertical profile, which is normally used in the optimal estimation method. Thus, the vertical resolution was fixed, and the averaging kernel was the same for all averaged spectra, as discussed by Nagahama et al. (1999). The vertical resolutions were estimated to be $\sim 12, \sim 17, \sim 21$, and $\sim 26 \mathrm{~km}$ at altitudes of $35,40,45$, and $50 \mathrm{~km}$ respectively.

\subsection{Error analysis}

Uncertainties in the input parameters in the retrieval process influence the precision of the results in the form of random errors. Four sources of random error were evaluated: (1) the difference between the actual and assumed vertical profiles of temperature, (2) the influence of the choice of the a priori profile of $\mathrm{ClO}$, (3) random noise in the spectral data, and (4) random error in the measurement of the atmospheric optical depth. In addition, systematic errors due to the observing system and the measurement procedure were evaluated by comparison of the observation data with data obtained in previous observations with different instruments (see Sect. 4.3).

\subsubsection{Difference in the temperature profiles}

We used the vertical temperature profile derived from NCEP reanalysis data below $49 \mathrm{~km}$ and from CIRA86 data above $49 \mathrm{~km}$, as mentioned in Sect. 3.2. Differences between the assumed and actual temperature profiles led to error in the forward model calculation in the retrieval process. This error was evaluated numerically as follows. A virtual temperature profile was constructed by the addition of a constant offset to the actual temperature profile; this virtual temperature profile 

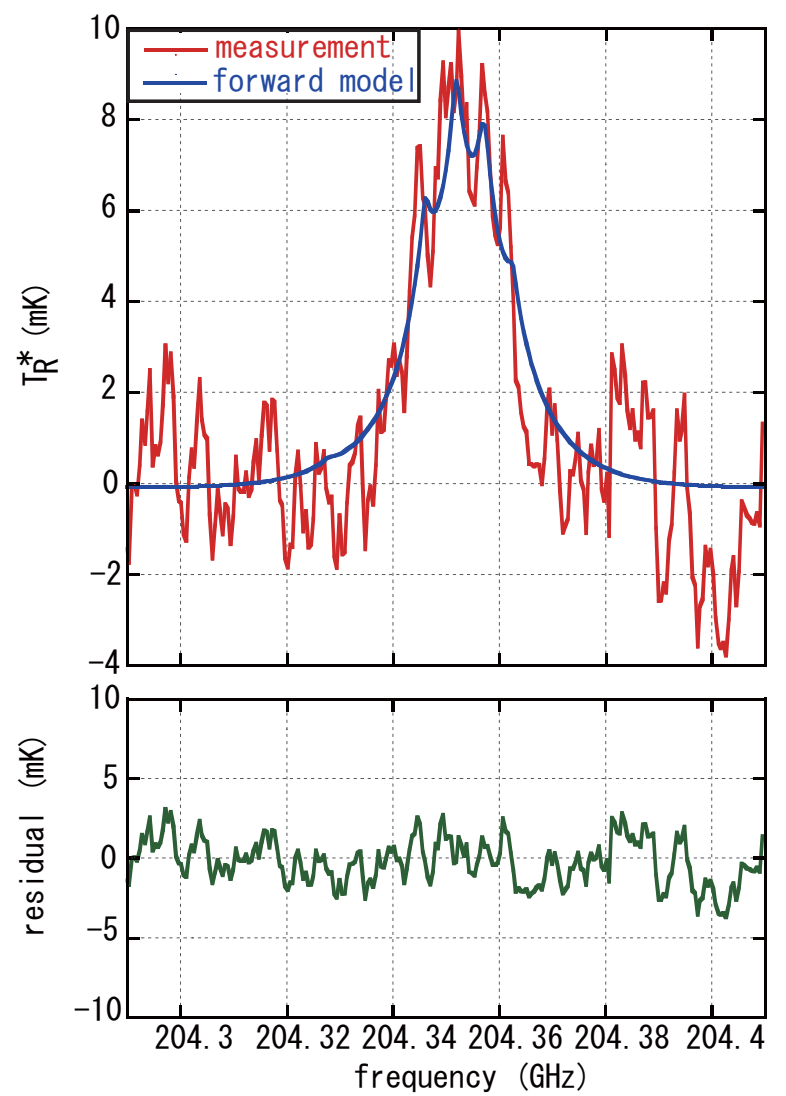

Fig. 3. (Top) Averaged ClO spectrum obtained at 12:00-15:00 LT from 5 to 16 December 2009 (red) and the fitting curve with the forward model (blue). (Bottom) Residual of the fitting by the forward model calculation.

was then used to run the retrieval program, and the retrieval results derived from the original and virtual temperature profiles were compared. The typical amplitudes of diurnal variation of the stratospheric temperature have been estimated to be $\sim 1 \mathrm{~K}$ at $40 \mathrm{~km}$ and $\sim 4 \mathrm{~K}$ at $60 \mathrm{~km}$ in the vicinity of latitude $20^{\circ} \mathrm{S}$ (Huang et al., 2010). In this work, a constant offset of $5 \mathrm{~K}$ was added to the original profile to obtain the estimated error in the mixing ratio at each altitude (dashed line in Fig. 6). The error was estimated to be smaller than $\sim 1 \%$ between 40 and $50 \mathrm{~km}$, but the error abruptly increased to $\sim 5 \%$ below $35 \mathrm{~km}$.

\subsubsection{Error due to the a priori profile of $\mathrm{ClO}$}

In the inversion analysis, as in the optimal estimation method, the choice of the a priori profile inevitably affects the retrieval results. Large diurnal variation of $\mathrm{ClO}$ mixing ratios has been reported previously (e.g., Solomon et al., 1984; Ricaud et al., 1997), and it is important that the effect of diurnal variation is considered assuming the a priori profiles. In this study, a single a priori profile was used for all the averaged spectra; the a priori profile used was a vertical profile

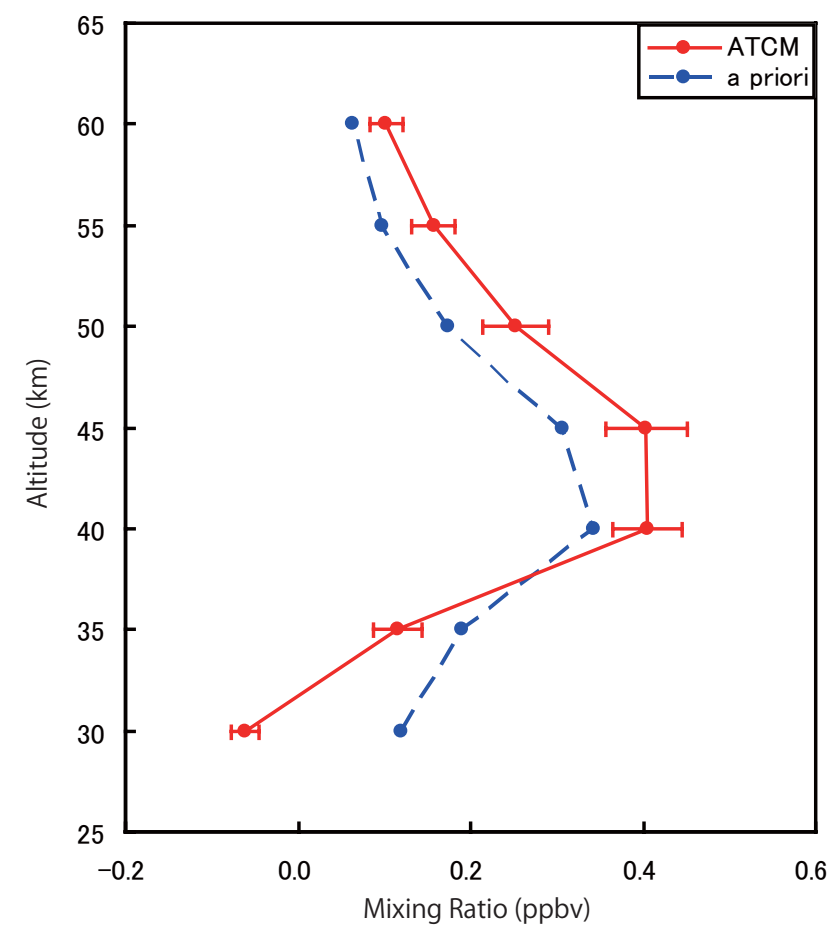

Fig. 4. Vertical profile of $\mathrm{ClO}$ mixing ratio retrieved from the averaged spectrum obtained at 12:00-15:00 LT from 5 to 16 December 2009 (red solid line) and a priori profile (blue dashed line).

of average daytime and nighttime values from the MIPAS model atmosphere in the mid-latitude region. The typical error was estimated numerically in a manner similar to that used to estimate the error due to the difference between the actual and assumed temperature profiles. The mixing ratio for the daytime spectrum was retrieved by using two different types of a priori profiles: the daytime a priori profile and the day-and-night average a priori profile. Then the retrieved profiles for the two types of a priori profiles were compared. For the nighttime spectrum, the same comparison was made, but the nighttime a priori profile was used instead of the daytime profile. The difference between the retrieved profiles obtained with the two different a priori profiles represents the numerically estimated error (dashed-dotted and dashedtwo-dotted lines in Fig. 6). Although the absolute error amplitudes for daytime and nighttime spectra were almost the same, the percentile error was larger for the nighttime spectrum, which reflected the smaller mixing ratio at nighttime. Between 40 and $50 \mathrm{~km}$, the error was less than $\sim+13 \%$ for daytime spectra and less than $\sim-22 \%$ for nighttime spectra.

\subsubsection{Random noise on the spectrum}

The influence of noise, which is generated mainly by the receiver system, was estimated. Virtual spectral data were generated by the addition of random noise to a forward model spectrum calculated from a virtual but realistic vertical 


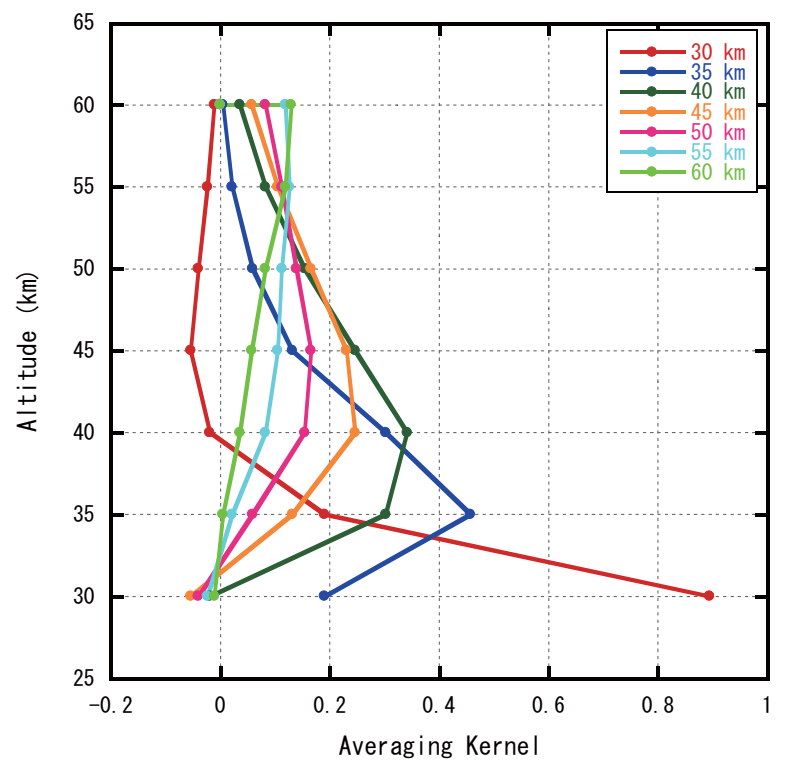

Fig. 5. Averaging kernels for the retrieval calculation between $30 \mathrm{~km}$ and $60 \mathrm{~km}$.

profile of $\mathrm{ClO}$. Then the retrieval algorithm was applied to the virtual spectrum, and the retrieved vertical profile was compared with the original input profile (solid line in Fig. 6). Because the typical value of the rms noise in the averaged $\mathrm{ClO}$ spectra was $1.8 \mathrm{mK}$, random noise of $1.8 \mathrm{mK}$ was added to the forward model spectrum. The error due to random noise was lowest at $40 \mathrm{~km}(\sim 11 \%)$, and the error increased to $\sim 21 \%$ at $50 \mathrm{~km}$.

\subsubsection{Random error related with the atmospheric correction}

The atmospheric optical depth was estimated by the skytipping method. In this method, $T_{\text {trop }}$ is assumed to be equal to the hot reference temperature, $T_{\text {hot }}$. Then the difference, $\Delta P$, between the output power for the hot reference, $P_{\text {hot }}$, and the output power for the observing sky, $P_{\text {sky }}$, at an elevation angle of EL, is given by

$$
\begin{aligned}
\Delta P & =P_{\mathrm{hot}}-P_{\text {sky }} \\
& =\alpha T_{\mathrm{hot}} e^{\left(-\tau A_{\mathrm{EL}}\right)},
\end{aligned}
$$

where $A_{\mathrm{EL}}$ is the air mass factor. The temperature of the hot reference is stable and equal to room temperature $(300 \mathrm{~K})$, which was well controlled by an air conditioner. Then, $\ln (\Delta P)$ becomes a function of $\tau$ and $A_{\mathrm{EL}}$ as shown below:

$\ln (\Delta P)=-\tau A_{\mathrm{EL}}+\ln \left(\alpha T_{\mathrm{hot}}\right)$.

In this equation, $\tau$ is expressed like a proportionality constant. We can determine $\tau$ by measuring the values of $\Delta P$ for several elevation angles (that is, by the sky-tipping method). However, the actual sky temperature changes from hour to

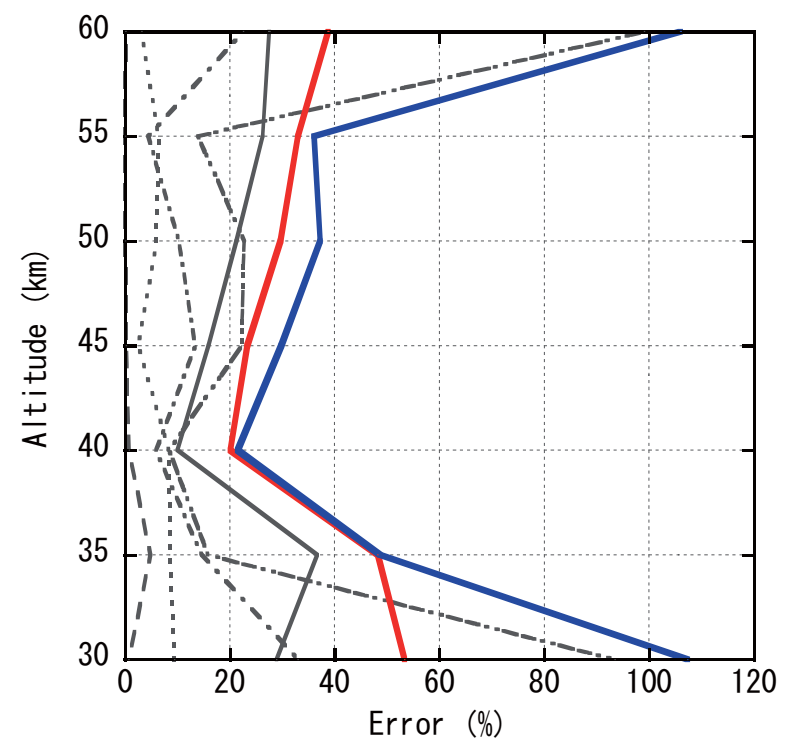

Fig. 6. Estimated random errors due to temperature profile (dash), a priori profile (day: dash-dot, night: dash-dot-dot), random noise on the spectrum (solid), and atmospheric correction (dot). Total of the random errors (i.e., root sum square of the individual errors) are indicated by colored solid lines (red for daytime and blue for nighttime).

hour, and the difference between the actual effective sky temperature and the hot reference temperature leads to error in $\tau$. The effective sky temperature is typically $\sim 7 \mathrm{~K}$ lower than the surface temperature (Parrish et al., 1988). At the observation site in December 2009, the outside surface temperature was $\sim 300 \mathrm{~K}$ during the day and $\sim 275 \mathrm{~K}$ during the night. Variation of the effective sky temperature between 270 and $300 \mathrm{~K}$ leads to a maximum variation of $\sim 12 \%$ in the optical depth $\tau$. The error in $\tau_{\text {plate }}$ is almost the same as the error in $\tau$, because $\tau_{\text {plate }}$ was estimated from $\tau$ by means of Eq. (11). The influence of the optical depth and the sky temperature errors on the retrieval calculation of the mixing ratio was estimated to be $2-7 \%$ at 40 to $50 \mathrm{~km}$ (dotted line in Fig. 6).

\subsubsection{Total of the random errors}

The sum of the random errors due to the four sources described above can be expressed in terms of the root sum square of each error, because the four sources of error were considered to be independent of one another (red and blue solid lines in Fig. 6). Among the four sources of error, the a priori profile and the spectral noise were similar to each other and accounted for most of the total error. In addition, the error bar in Fig. 4 shows the total of the random error. Because the information content has vanished, the retrieved profile approaches the a priori profile, and the error bars get smaller the further away from the altitude region, which is from 40 to $50 \mathrm{~km}$. 

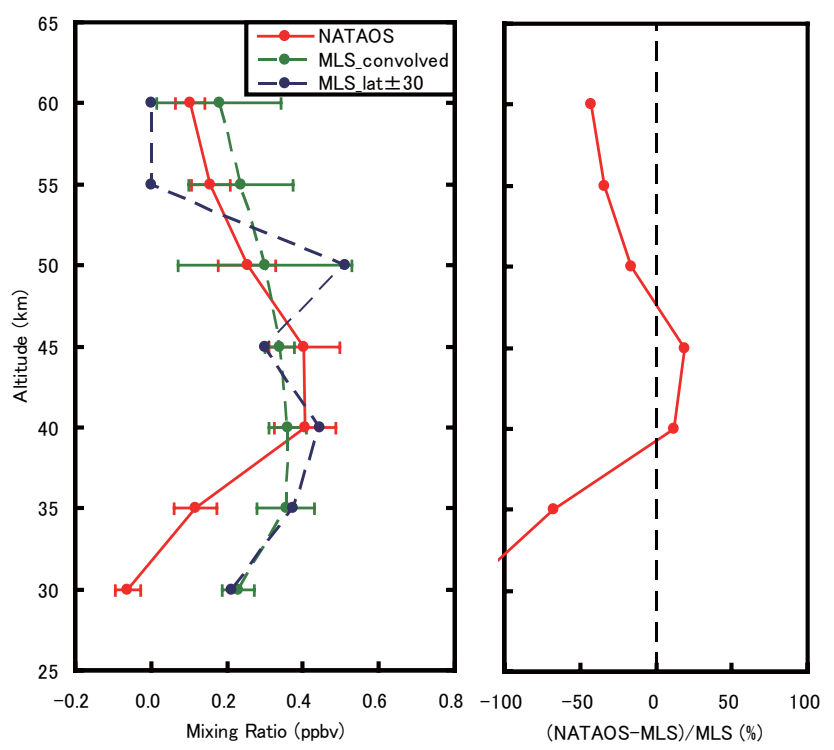

Fig. 7. (Left) Comparison of the vertical $\mathrm{ClO}$ profiles measured by NATAOS radiometer and AURA/MLS averaged for corresponding location (longitude: $\pm 30^{\circ}$ and latitude $\pm 2^{\circ}$ from Atacama) and time (12:00-15:00 LT at the position of the AURA satellite between 5 and 16 December 2009). For the MLS profiles, blue and green dashed lines correspond to unconvolved and convolved profiles by the NATAOS averaging kernel, respectively. (Right) Percentage difference between NATAOS radiometer and convolved MLS profiles.

\subsubsection{Systematic errors}

Systematic errors were due mainly to biases related to the characteristics of the observation system, the methods used to calibrate the signal intensity, and molecular spectral line parameters.

In the measurement system in Atacama, two black bodies at different physical temperatures were used as intensity references. The temperature of the cold reference was expected to be stable. However, the cold reference was observed through a vessel made of styrene foam, the opacity of which effectively increased the brightness temperature of the cold reference by less than $\sim 3 \%$. The hot load was at room temperature, which varied roughly within $5 \mathrm{~K}$ between day and night; therefore, the intensity scale of the spectra varied at most by $\sim \pm 2 \%$ between day and night.

Another systematic error was related to the intensity calibration and was due to the imbalance of the sideband ratio of the heterodyne mixer receiver. The SIS mixer was operated in DSB mode in this study. We assumed the gains of both sidebands are equal based on the observation of ozone spectrum at nearby frequency, but, if the gains of the two sidebands were not exactly equal, the inequality would result in a small systematic error in the intensity scale. However, precise measurement of the side-band ratio for a SIS mixer is difficult in practice, and the accuracy of the intensity calibration was
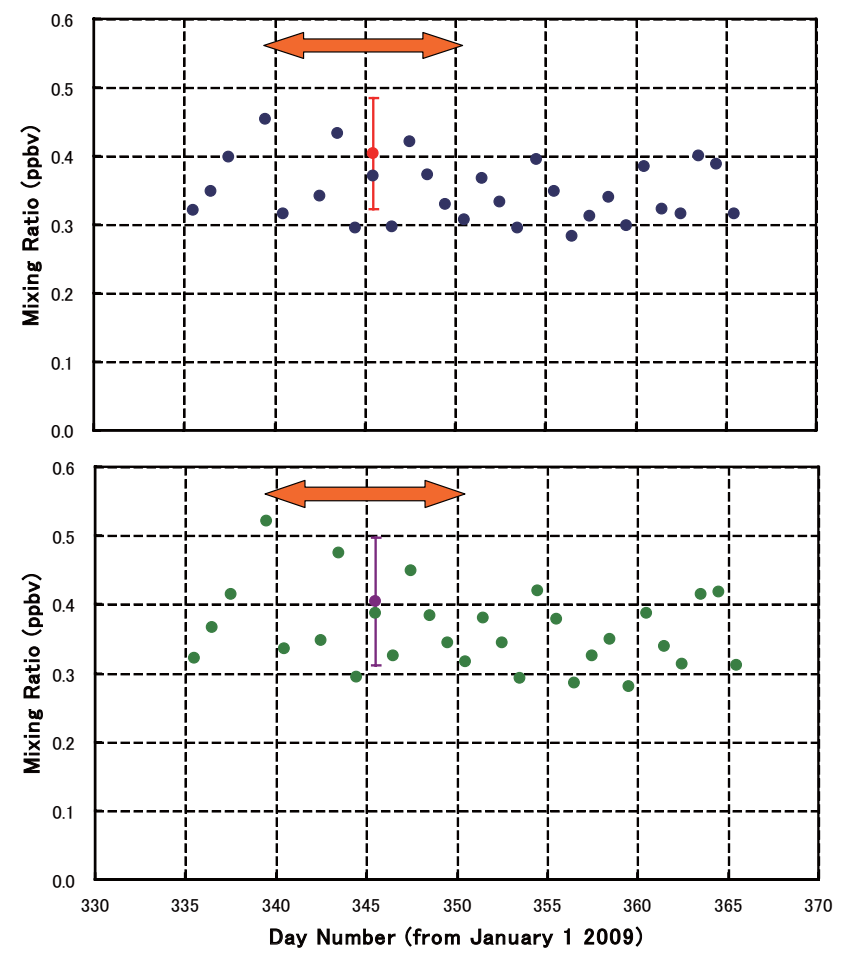

Fig. 8. Time series of daily average of the selected MLS ClO mixing ratio (within 12:00-15:00 LT) over Atacama at $40 \mathrm{~km}$ (top panel) and $45 \mathrm{~km}$ (bottom panel), respectively. $\mathrm{ClO}$ mixing ratio derived from the averaged spectrum obtained by NATAOS radiometer is superposed. The arrow indicates the averaging period of the NATAOS measurement, from December 5 to 16, 2009.

evaluated by comparisons with data obtained with other instruments.

For the spectral line parameters, we cannot evaluate qualitatively in this study, because no error information is found in JPL Submillimeter, Millimeter, and Microwave Spectral Line Catalog (Pickett et al., 1998). But they are potential causes of systematic error.

\subsection{Comparison with the satellite measurements}

To evaluate the total systematic error, the retrieval results for Atacama were compared with the results for other satellite measurements. First, $\mathrm{ClO}$ profiles were selected from the AURA/MLS data (ver. 2.2) collected within $\pm 2^{\circ}$ in latitude and $\pm 30^{\circ}$ in longitude from the position of the Atacama station (NATAOS) and at times between 12:00 and 15:00 LT from 5 to 16 December 2009 for each observation point of MLS. A total of 35 profiles were selected by means of these criteria, and the profiles were averaged and convolved by the NATAOS averaging kernel to equalize the vertical resolution and response; the vertical resolution of the MLS data is higher than that of NATAOS retrieval results. The convolved and the original MLS and NATAOS profiles are shown in Fig. 7. The error bars for the MLS mixing ratios in the figure 


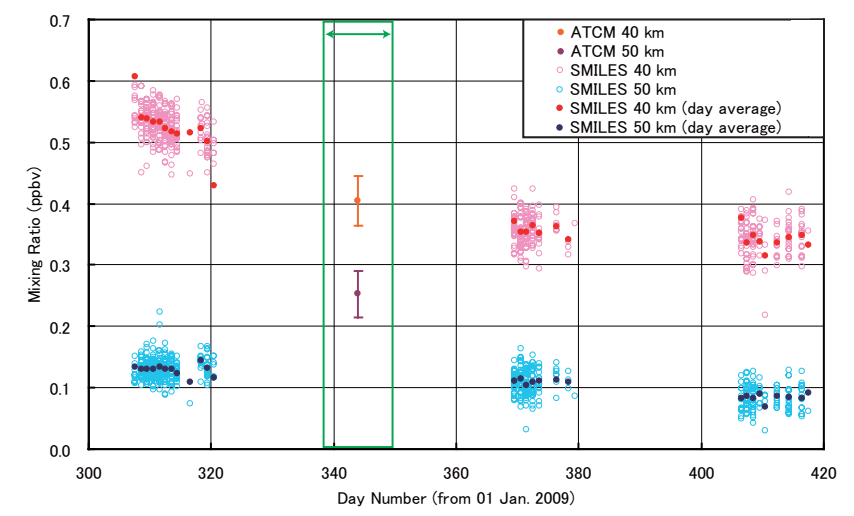

Fig. 9. The $\mathrm{ClO}$ mixing ratio at $40 \mathrm{~km}$ and $50 \mathrm{~km}$ obtained by JEM/SMILES (ver. 1.3) and NATAOS radiometer between November 2009 and February 2011. The SMILES data were selected within $\pm 2^{\circ}$ in latitude and $\pm 30^{\circ}$ in longitude from Atacama and with an observational time of 12:00-15:00 LT. Pink and light blue open circles show the $\mathrm{ClO}$ mixing ratio obtained by SMILES at $40 \mathrm{~km}$ and $50 \mathrm{~km}$, respectively. Red and blue circles show daily average of $\mathrm{ClO}$ mixing ratio obtained by SMILES at $40 \mathrm{~km}$ and $50 \mathrm{~km}$, respectively. Orange and purple circles show the $\mathrm{ClO}$ mixing ratio obtained by NATAOS radiometer at $40 \mathrm{~km}$ and $50 \mathrm{~km}$, respectively. The arrow shows the period of averaging NATAOS data, from 5 to 16 December 2009.

were derived from the precision values attached to the individual MLS data profiles. Santee et al. (2008) mentioned that the MLS mixing ratio below $1.0 \mathrm{hPa}$, corresponding to above $\sim 50 \mathrm{~km}$, is unsuitable for scientific use. On the other hand, the NATAOS profile is not reliable below $40 \mathrm{~km}$ as mentioned in Sect. 4.2.5. Thus, we can make fruitful comparison only at 40 and $45 \mathrm{~km}$.

Figure 8 shows the time series of daily average of the selected MLS ClO mixing ratio convolved by the NATAOS averaging kernels at $40 \mathrm{~km}$ and $45 \mathrm{~km}$. The 12-day averages of the NATAOS mixing ratios are superposed in Fig. 8 as well. Both measurements of MLS and NATAOS show good agreement within errors, but the mixing ratios obtained by NATAOS show slightly positive trend relative to those of MLS ( $\sim 13 \%$ and $\sim 18 \%$ at 40 and $45 \mathrm{~km}$, respectively).

In another attempt to evaluate the systematic error, the NATAOS retrieval results were compared with the Japanese Experiment Module (JEM) Superconducting SubmillimeterWave Limb-Emission Sounder (SMILES) data. SMILES has three observing frequency bands, and two of the three bands can be operated simultaneously. Unfortunately, band $\mathrm{C}$, which covers the $\mathrm{ClO}$ line frequency, was not observed during our observational period in Atacama. Therefore, direct comparison of the NATAOS data with the SMILES data is difficult, but the NATAOS results could be roughly evaluated against the SMILES data obtained in November 2009 and January 2010. Figure 9 shows the time series of ClO mixing ratios at 40 and $50 \mathrm{~km}$ obtained by SMILES, along with the mixing ratios determined at Atacama. The plotted data

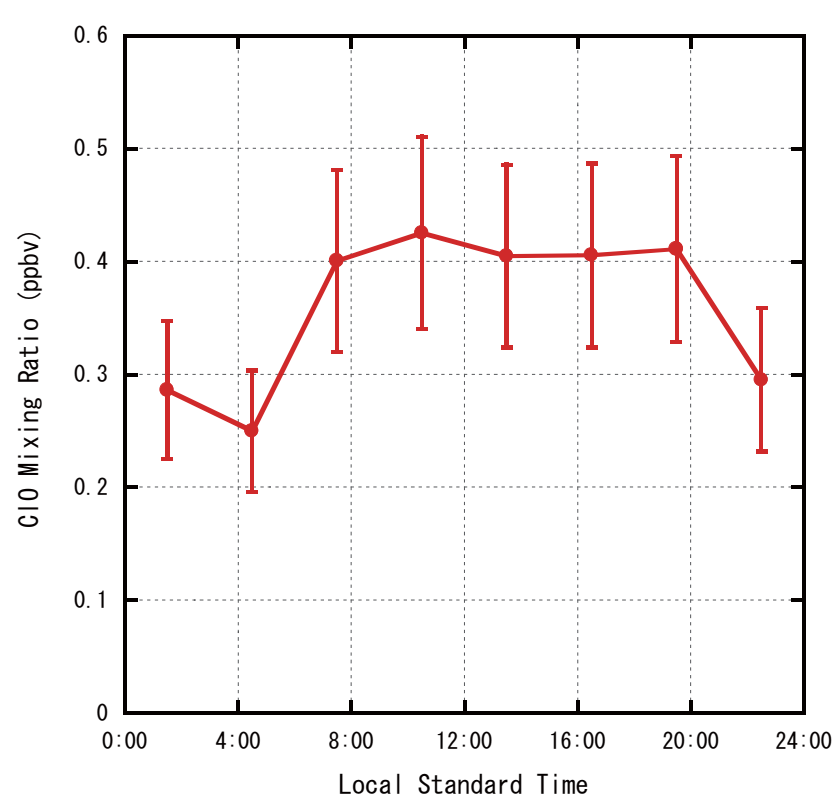

Fig. 10. Diurnal variation of $\mathrm{ClO}$ mixing ratio at $40 \mathrm{~km}$ measured by NATAOS radiometer for a period of 5-16 December 2009.

were selected from the version 1.3 (test release) dataset by application of the same positional criteria used for selecting the MLS data. The mixing ratio determined from NATAOS measurements at $40 \mathrm{~km}$ looks reasonable, roughly on the line between the November and January SMILES mixing ratios. The SMILES mixing ratios at $50 \mathrm{~km}$ show a slightly decreasing trend but can be regarded as almost constant compared with the ratios at $40 \mathrm{~km}$. The NATAOS mixing ratio at $50 \mathrm{~km}$ appears to be $\sim 80 \%$ higher than the average SMILES value, but, when the JEM/SMILES profile was convoluted with the NATAOS averaging kernel at $50 \mathrm{~km}$, the discrepancy was reduced to $\sim 7 \%$. Therefore, it is likely that the ground-based measurements at NATAOS were consistent with the SMILES measurements within the errors, although the exactly coincident datasets required for a definitive direct comparison do not exist.

In the results of comparison with NATAOS and satellites, the most reliable mixing ratio values in this study were those between $40 \mathrm{~km}$ and $50 \mathrm{~km}$. This range includes the altitude where the stratospheric $\mathrm{ClO}$ mixing ratio peaks.

\subsection{Diurnal variation of stratospheric ClO observed over Atacama}

The photochemistry of chlorine reservoir species such as $\mathrm{ClONO}_{2}, \mathrm{HOCl}$, and $\mathrm{HCl}$ play an important role in regulating the diurnal variation of ClO levels (e.g., Ko and Sze, 1984; Froidevaux et al., 1985).

Figure 10 shows the diurnal variation of $\mathrm{ClO}$ at $40 \mathrm{~km}$ averaged over 5-16 December 2009 over Atacama $\left(23^{\circ} \mathrm{S}\right)$. The horizontal axis is the local time, LT, in Chile. The vertical profiles are derived from the averaged spectra for every $3-\mathrm{h}$ 
bin from 00:00 to 24:00 over the 12 days. During this period, the sunrise time and the sunset time were 05:30 and 19:30, respectively, and the culmination time was 12:30 at Atacama. The mixing ratio of $\mathrm{ClO}$ quickly increases after the sunrise and reaches up to the daytime plateau level at the time slot of 06:00-09:00 LT. The amplitude of the diurnal variation is $\sim 33 \%$ of the daytime average at $40 \mathrm{~km}$. The time variation of the NATAOS data shows a pattern similar to that of the previous satellite data observed in the northern mid-latitude region (Ricaud et al., 2000) after making convolution of the satellite data by the NATAOS averaging kernel.

We plan to run a model calculation that is fitted for the Atacama site to compare with the observational results. We intend to make such a comparison with model calculation in the next paper.

\section{Summary}

This paper has presented the vertical profiles and the diurnal variation of $\mathrm{ClO}$ in the summertime in the southern midlatitude region, based on the new millimeter-wave spectroscopic measurements made in the Atacama highland, Chile. We have described the specification of the new measurement system, the observing method, and the retrieval method of vertical mixing ratio profiles. The measurement errors have been evaluated numerically, and the precision of the $\mathrm{ClO}$ mixing ratio is estimated from $20 \%$ to $30 \%$ in an altitude range from $40 \mathrm{~km}$ to $50 \mathrm{~km}$. We have presented the diurnal variation of the $\mathrm{ClO}$ over $24 \mathrm{~h}$ at $40 \mathrm{~km}$ during 5-16 December 2009. The variation amplitude and variation pattern at $40 \mathrm{~km}$ are consistent with the previous study in the northern mid-latitude presented by Ricaud et al. (2000). We intend to continue further observations to reveal the seasonal variations as well as the diurnal variation and intend to make model calculations to compare the observational results.

Acknowledgements. This work was financially supported by a grant-in-aid for Scientific Research (KAKENHI, No. 18340150, No. 18403008, No. 20403009, and No. 23340145) from JSPS, and was also supported in part of JEM/SMILES mission which is a joint project of Japan Aerospace Exploration Agency (JAXA) and National Institute of Information and Communications Technology (NICT).

Edited by: J. Notholt

\section{References}

Amano, T., Hirota, E., and Morino, Y.: Microwave spectrum of the ClO radical, J. Mol. Spectrosc., 27, 257-265, 1968.

de Zafra, R. L., Emmons L. K., Reeves, J. M., and Shindell, D. T.: An overview of millimeter-wave spectroscopic measurements of chlorine monoxide at Thule, Greenland, February-March, 1992:
Vertical profiles, diurnal variation, and longer-term trends, Geophys. Res. Lett., 21, 1271-1274, doi:10.1029/93GL01677, 1994.

Emmons, L. K., Shindell, D. T., Reeves, J. M., and de Zafra, R. L.: Stratospheric $\mathrm{ClO}$ profiles from McMurdo Station, Antarctica, spring 1992, J. Geophys. Res., 100, 3049-3055, doi:10.1029/94JD02962, 1995.

Froidevaux, L., Allen, M., and Yung, Y. L.: A critical analysis of CLO and $\mathrm{O}_{3}$ in the mid-latitude stratosphere, J. Geophys. Res., 90, 12999-13029, doi:10.1029/JD090iD07p12999, 1985.

Gustincic, J. J.: A quasi-optical receiver design, IEEE MTT-S, 99102, doi:10.1109/MWSYM.1977.1124373, 1977.

Huang, F. T., McPeters, R. D., Bhartia, P. K., Mayr, H. G., Frith, S. M., Russell III, J. M., and Mlynczak, M. G.: Temperature diurnal variations (migrating tides) in the stratosphere and lower mesosphere based on measurements from SABER on TIMED, J. Geophys. Res., 115, D16121, doi:10.1029/2009JD013698, 2010.

Jones, A., Urban, J., Murtagh, D. P., Sanchez, C., Walker, K. A., Livesey, N. J., Froidevaux, L., and Santee, M. L.: Analysis of $\mathrm{HCl}$ and $\mathrm{ClO}$ time series in the upper stratosphere using satellite data sets, Atmos. Chem. Phys., 11, 5321-5333, doi:10.5194/acp11-5321-2011, 2011.

Ko, M. K. W. and Sze, N. D.: Diurnal variation of ClO: Implications for the stratospheric chemistries of $\mathrm{ClONO}_{2}$, $\mathrm{HOCl}$, and $\mathrm{HCl}$, J. Geophys. Res., 89, 11619-11632, doi:10.1029/JD089iD07p11619, 1984.

Lait, L., Newman, P., and Schoeberl, R.: The Goddard Automailer, available at: http://code916.gsfc.nasa.gov/Data_services/, 2009.

Mahieu, E., Zander, R., Duchatelet, P., Hannigan, J. W., Coffey, M. T., Mikuteit, S., Hase, F., Blumenstock, T., Wiacek, A., Strong, K., Taylor, J. R., Mittermeier, R., Fast, H., Boone, C. D., McLeod, S. D., Walker, K. A., Bernath, P. F., and Rinsland, C. P.: Comparisons between ACE-FTS and groundbased measurements of stratospheric $\mathrm{HCl}$ and $\mathrm{ClONO}_{2}$ loadings at northern latitudes, Geophys. Res. Lett., 32, L15S08, doi:10.1029/2005GL022396, 2005.

Mizuno, A., Nagahama, T., Morihira, A., Ogawa, H., Mizuno, N., Yonekura, Y., Yamamoto, H., Nakane, H., and Fukui, Y.: Millimeter-wave radiometer for the measurement of stratospheric $\mathrm{ClO}$ using a superconductive (SIS) receiver installed in the southern hemisohere, Int. J. Infrared Milli., 23, 981-995, doi:10.1023/A:1019618917005, 2002.

Molina, M. and Rowland, F. S.: Stratospheric sink for chlorofluoromethanes: Chlorine atomic-catalysed destruction of ozone, Nature, 249, 810-812, doi:10.1038/249810a0, 1974.

Nagahama, T., Nakane, H., Fujinuma, Y., Ninomiya, M., Ogawa, H., and Fukui, Y.: Ground-based millimeter-wave observations of ozone in the upper stratosphere and mesosphere over Tsukuba, Earth Planets Space, 51, 1287-1296, 1999.

Nedoluha, G. E., Connor, B. J., Barrett, J., Mooney, T., Parrish, A., Boyd, I., Wrotny, J. E., Gomez, R. M., Koda, J., Santee, M. L., and Froidevaux, L.: Ground-based measurements of $\mathrm{ClO}$ from Mauna Kea and intercomparisons with Aura and UARS MLS, J. Geophys. Res., 116, D02307, doi:10.1029/2010JD014732, 2011.

Raffalski, U., Klein, U., Franke, B., Langer, J., Sinnhuber, B.-M., Trentmann, J., Künzi, K. F., and Schrems, O.: Ground based millimeter-wave observations of Arctic chlorine activation during winter and spring 1996/97, Geophys. Res. Lett., 25, 33313334, doi:10.1029/98GL52487, 1998. 
Parrish, A., de Zafra, R. L., Solomon, P. M., and Barrett, J. W.: A ground-based technique for millimeter wave spectroscopic observations of stratospheric trace constituents, Radio Sci., 23, 106-118, doi:10.1029/RS023i002p00106, 1988.

Rees, D., Barnett, J. J., and Labitzke, K.: COSPAR International Reference Atmosphere: 1986, Part II: Middle atmosphere models, Adv. Space Res., 12, 3-5, doi:10.1016/0273-1177(90)90384C, 1990 .

Ricaud, P., de La Noë, J., Lauqué, R., and Parrish, A.: Analysis of stratospheric chlorine monoxide measurements recorded by a ground-based radiometer located at the Plateau de Bure, France, J. Geophys. Res., 102, 1423-1439, doi:10.1029/96JD01724, 1997.

Ricaud, P., Chipperfield, M. P., Waters, J. W., Russell III, J. M., and Roche, A. E.: Temporal evolution of chlorine monoxide in the middle stratosphere, J. Geophys. Res., 105, 4459-4469, doi:10.1029/1999JD900995, 2000.

Pickett, H. M., Poynter, R. L., Cohen, E. A., Delitsky, M. L., Pearson, J. C., and Müller, H. S. P.: Submillimeter, millimeter, and microwave spectral line catalog, J. Quant. Spectrosc. Ra., 60, 883-890, doi:10.1016/S0022-4073(98)00091-0, 1998.

Rinsland, C. P., Mahieu, E., Zander, R., Jones, N. B., Chipperfield, M. P., Goldman, A., Anderson, J., Russell III, J. M., Demoulin, P., Notholt, J., Toon, G. C., Blavier, J.-F., Sen, B., Sussmann, R., Wood, A., Meier, D. W. T., Griffith, L. S., Chiou, F. J., Murcray, T. M., Stephen, F., Hase, S., Mikuteit, A., Schulz, S. W., and Blumenstock, T.: Long-term trends in inorganic chlorine from ground-based infrared solar spectra: Past increases and evidence for stabilization, J. Geophys. Res., 108, 4252, doi:10.1029/2002JD003001, 2003.

Rodgers, C. D.: Retrieval of atmospheric temperature and composition from remote measurements of thermal radiation, Rev. Geophysics, 14, 609-624, doi:10.1029/RG014i004p00609, 1976.
Santee, M. L., Lambert, A., Read, W. G., Livesey, N. J., Manney, G. L., Cofield, R. E., Cuddy, D. T., Daffer, W. H., Drouin, B. J., Froidevaux, L., Fuller, R. A., Jarnot, R. F., Knosp, B. W., Perun, V. S., Snyder, W. V., Stek, P. C., Thurstans, R. P., Wagner, P A., Waters, J. W., Connor, B., Urban, J., Murtagh, D., Ricaud, P., Barrett, D., Kleinboehl, A., Kuttippurath, J., Kullmann, H., von Hobe, M., Toon, G. C., and Stachnik,R. A.: Validation of the Aura Microwave Limb Sounder ClO measurements, J. Geophys. Res., 113, D15S22, doi:10.1029/2007JD008762, 2008.

Schieder, R. and Kramer, C., Optimization of heterodyne observations using Allan variance measurements, Astron. Astrophys., 373, 746-756, doi:10.1051/0004-6361:20010611, 2001.

Solomon, P. M., de Zafra, R., Parrish, A., and Barrett, J. W.: Diurnal variation of stratospheric chlorine monoxide: A critical test of chlorine chemistry in the ozone layer, Science, 224, 1210-1214, doi:10.1126/science.224.4654.1210, 1984.

Tucker, J. R. and Feldman, M. J.: Quantum detection at millimeter wavelengths, Rev. Mod. Phys., 57, 1055-1113, doi:10.1103/RevModPhys.57.1055, 1985.

Ulich, B. L., Davis, J. H., Rhodes, P. J., and Hollis, J.: Absolute brightness temperature measurements at 3.5mm wavelength, IEEE T. Antenn. Propag., 28, 367-377, doi:10.1109/TAP.1980.1142330, 1980.

WMO (World Meteorological Organization): Scientific Assessment of Ozone Depletion: 2010, Geneva, 2011.

Zander, R., Mahieu, E., Gunson, M. R., Abrams, M. C., Chang, A. Y., Abbas, M., Aellig, C., Engel, A., Goldman, A., Irion, F. W., Kämpfer, N., Michelson, H. A., Newchurch, M. J., Rinsland, C. P., Salawitch, R. J., Stiller G. P., and Toon, G. C.: The 1994 northern mid latitude budget of stratospheric chlorine derived from ATMOS/ATLAS-3 observations, Geophys. Res. Lett., 23, 2357 2360, doi:10.1029/96GL01792, 1996. 